\title{
Association of leisure-time sedentary behavior with fast food and carbonated soft drink consumption among 133,555 adolescents aged $12-15$ years in 44 low- and middle-income countries
}

\author{
Garcia Ashdown-Franks ${ }^{1,2^{*}}$ (D), Davy Vancampfort ${ }^{3,4}$, Joseph Firth ${ }^{5,6}$, Lee Smith7, Catherine M. Sabiston²,
} Brendon Stubbs ${ }^{1,2,8}$ and Ai Koyanagi ${ }^{9,10}$

\begin{abstract}
Background: Rates of sedentary behavior (SB), fast food and carbonated soft drink consumption are increasing worldwide, with steeper increases being observed in low- and middle-income countries (LMICS) in recent years. Given that these behaviors have been linked to adverse health outcomes among adolescents, this presents a new but rapidly growing challenge to human health in these under-resourced nations. However, very little is known about the associations between SB and fast food or soft drink consumption among adolescents in LMICS.

Methods: Thus, data from the Global school-based Student Health Survey (GSHS) were cross-sectionally analyzed in 133,555 adolescents aged 12-15 years from 44 LMICs [mean (SD) age 13.8 (1.0) years; 49\% females]. The data were collected in the form of self-report questionnaires. Associations were assessed with multivariable logistic regression analysis and meta-analysis.

Results: The overall prevalence of fast food consumption (at least once in previous 7 days) and carbonated soft drink consumption (at least once per day during past 30 days) were 49.3 and $43.8 \%$, respectively. The overall pooled estimates based on a meta-analysis with random effects for the association of $\geq 3 \mathrm{~h} /$ day of SB with fast food consumption and soft drink consumption using country-wise estimates were $\mathrm{OR}=1.35(95 \% \mathrm{Cl}=1.27-1.43$, $\left.\mathrm{I}^{2}=62.1 \%\right)$.) and $\mathrm{OR}=1.26\left(95 \% \mathrm{Cl}=1.19-1.34 ; \mathrm{I}^{2}=54.3 \%\right)$, respectively. Spending $>8 \mathrm{~h} /$ day of SB compared to $<1 \mathrm{~h}$ /day in females was associated with significantly higher odds for fast food $(\mathrm{OR}=1.61,95 \% \mathrm{Cl}=1.38-1.88)$ and soft drink consumption ( $\mathrm{OR}=1.91,95 \% \mathrm{Cl}=1.60-2.28)$.
\end{abstract}

Conclusions: Future interventions to address unhealthy behaviors in adolescents should take into account the interrelated nature of SB and unhealthy dietary habits, and seek to further understand the mechanisms linking these behaviors in the LMIC context.

Keywords: Adolescents, Sedentary behavior, Fast food consumption, Soft drink consumption, Low- and middleincome countries (LMICS)

\footnotetext{
* Correspondence: Garcia.ashdown_franks@kcl.ac.uk

${ }^{1}$ Department of Psychological Medicine, Institute of Psychiatry, Psychology and Neuroscience, King's College London, De Crespigny Park, Box, London SE5 8AF, UK

${ }^{2}$ Department of Exercise Sciences, University of Toronto, 55 Harbord Street,

Toronto, Ontario M5S 2W6, Canada

Full list of author information is available at the end of the article
}

(c) The Author(s). 2019 Open Access This article is distributed under the terms of the Creative Commons Attribution 4.0 International License (http://creativecommons.org/licenses/by/4.0/), which permits unrestricted use, distribution, and reproduction in any medium, provided you give appropriate credit to the original author(s) and the source, provide a link to the Creative Commons license, and indicate if changes were made. The Creative Commons Public Domain Dedication waiver (http://creativecommons.org/publicdomain/zero/1.0/) applies to the data made available in this article, unless otherwise stated. 


\section{Background}

Sedentary behavior (SB) (energy expenditure $\leq 1.5$ metabolic equivalents of task (METs) while in a sitting or reclining posture during waking hours), is increasing rapidly in low and middle-income countries (LMICs) [24], owing to the introduction of both mechanized systems and digital technologies reducing the need for occupational and leisure-time physical activity [27]. There is increasing evidence that SB is associated with various negative health outcomes such as obesity, non-communicable diseases (NCDs) (e.g., diabetes, cardiovascular diseases, cancer) and premature mortality [4, 29]. These negative health outcomes of SB have been found throughout the life course including adolescence [4, 29]. For example, it has been found that SB such as television viewing during adolescence, is a key predictor of negative health outcomes such as being overweight, poor fitness and raised cholesterol during adulthood [18]. As such, the time frame of adolescence represents an essential window to prevent such health issues.

Among adolescents, recent studies have shown that the adverse health outcomes in SB may also be explained by poor dietary habits [14]. For example, previous studies from high-income countries have found that SB is associated with higher intake of snacks, sugar-sweetened beverages and fast foods [14], which are known risk factors for obesity and other negative health outcomes such as type- 2 diabetes, hypertension and hypercholesterolemia and dental disease in adolescents $[8,26,30]$.

While there are several studies that have found a positive association between higher levels of $\mathrm{SB}$ and poor dietary habits among adolescents from high-income countries $[5,14,16,34]$, there is a notable lack of studies from LMICs. This is an important research gap as the fast food industry (which arose from high-income countries) is now spreading across LMICs, introducing widespread consumption of 'junk food' and sugary carbonated drinks, both of which are strongly associated with increased rates of obesity and cardiometabolic mortality in these nations [35]. Indeed, there have been increases reported in both prevalence of fast food outlets, and frequency of fast food consumption in LMICs [22]. Relatedly, sales and consumption of soft drinks are increasing more rapidly in LMICs than in high-income countries [3]. Furthermore, there is a rapid increase in obesity and NCDs in LMICs mainly due to changes in lifestyles [15, 31], while almost $80 \%$ of deaths from non-communicable diseases occur in LMICs [37]. Thus, it is of vital importance to assess how unhealthy behaviors such as SB and consumption of fast food or sugar-sweetened soft drinks, which are increasing rapidly in LMICs, cluster in this context to counteract the NCD epidemic. Findings from high-income countries cannot be assumed to be automatically applicable to LMICs as there are differences in terms of accessibility to devices such as televisions and computers as well as to fast food restaurants. Thus, studies from a variety of settings are necessary for the development of context-specific public health interventions and policies. As such, the purpose of this study was to examine the relationship between $\mathrm{SB}$, fast food consumption and carbonated soft drink consumption among adolescents in 41 LMICs.

\section{Methods}

\section{The survey}

Publicly available data from the Global School-Based Student Health Survey (GSHS) were analyzed. Details on this survey and the questionnaires can be found at http://www.who.int/chp/gshs and http://www.cdc.gov/ gshs. Briefly, the GSHS was jointly developed by the World Health Organization (WHO) and the US Centers for Disease Control and Prevention (CDC), and other United Nations (UN) allies. The core aim of this survey was to assess and quantify risk and protective factors of major non-communicable diseases. The survey draws content from the CDC Youth Risk Behavior Survey (YRBS) for which test-retest reliability has been established [9]. The survey used a standardized two-stage probability sampling design for the selection process within each participating country. For the first stage, schools were selected with probability proportional to size sampling. The second stage involved the random selection of classrooms which included students aged 13-15 years within each selected school. All students in the selected classrooms were eligible to participate in the survey regardless of age. Data collection was performed during one regular class period. The questionnaire was translated into the local language in each country and consisted of multiple choice response options; students recorded their response on computer scannable sheets which were distributed by survey administrators. Students were instructed that completing the survey is voluntary and that questions can be left blank if they do not want to reply at the beginning of the survey. All GSHS surveys were approved, in each country, by both a national government administration (most often the Ministry of Health or Education) and an institutional review board or ethics committee. Student privacy was protected through anonymous and voluntary participation, and written informed consent was obtained as appropriate from the students, parents and/ or school officials. Data were weighted for non-response and probability selection.

From all publicly available data, we selected all datasets that were nationally representative of students attending any type of school that included the variables 
pertaining to this analysis. High-income countries were excluded to focus on LMICs. If there were more than two datasets from the same country, we chose the most recent dataset. Thus, a total of 44 LMICs were included in the current study. For the included countries, the survey was conducted between 2009 and 2015, and consisted of 5 low-income, 26 lower middle-income, and 13 upper middle-income countries based on the World Bank classification at the time of the survey for the respective countries [36]. The list of countries included in the current study is provided in Table 1.

\section{Sedentary behavior (SB)}

$\mathrm{SB}$ was assessed with the question "How much time do you spend during a typical or usual day sitting and watching television, playing computer games, talking with friends, or doing other sitting activities?" with six response options: $<1,1-2,3-4,5-6,7-8$, and $>8 \mathrm{~h} /$ day. This excluded time at school and when doing homework. This variable was used as a five-category variable (5-6 and 7-8 $\mathrm{h} /$ day were merged as the proportion of those who replied $7-8 \mathrm{~h} /$ day was small) or a dichotomized variable ( $\geq 3 \mathrm{~h} /$ day or not) [17]. This question was based on the National Health and Nutrition Examination Survey (NHANES) questionnaire from 1999 to 2000, and modified for use in children.

\section{Fast food consumption}

Fast food consumption was assessed with the question "During the past 7 days, on how many days did you eat food from a fast food restaurant?" with country specific examples on fast food restaurants. The response options for this question were $0,1,2,3,4,5,6$, or 7 days. This variable was dichotomized as at least once or not.

\section{Carbonated soft drink consumption}

Consumption of carbonated soft drinks was assessed with the question "During the past 30 days, how many times per day did you usually drink carbonated soft drinks?" Country specific examples of carbonated soft drinks were provided (e.g., Carabao, Youki) and the student was instructed not to include diet soft drinks. Response options included 'I did not drink carbonated soft drinks during the past 30 days,' 'less than 1 time per day', ' 1 time per day,' 2 times per day,' 3 times per day,' 4 times per day', and ' 5 or more times per day'. This variable was dichotomized as $\geq 1$ time per day or not.

\section{Control variables}

Covariates included age, sex, food insecurity (proxy of socioeconomic status), and physical activity. As in a previous GSHS study, food insecurity was used as a proxy for socioeconomic status as there were no variables on socioeconomic status in the GSHS [2]. Specifically, this was assessed by the question "During the past 30 days, how often did you go hungry because there was not enough food in your home?" Response options were categorized as 'never,' 'rarely/sometimes', and 'most of the time/always' [28]. To assess levels of physical activity, questions that represented the PACE+ Adolescent Physical Activity Measure [32] were asked. This measure has been tested for validity and reliability [32]. The questions asked about the number of days in which the respondent engaged in physical activity of at least 60 min during the past 7 days. This did not include physical activity during physical education or gym classes. Those who engaged in $\geq 5$ days of at least $60 \mathrm{~min}$ of physical activity in a week were considered to have a sufficient amount of physical activity [17].

\section{Statistical analysis}

Statistical analyses were performed with Stata 14.1 (Stata Corp LP, College station, Texas). The analysis was restricted to those aged $12-15$ years. We used multivariable logistic regression analysis to estimate the association between SB (independent variable) and fast food or carbonated soft drink consumption (dependent variables) using the overall, sex-wise, and country-wise samples. The exposure variable was the five-category SB variable when the overall or sex-wise sample was used. However, for country-wise analyses, we used the dichotomized SB variable (i.e., $\geq 3 \mathrm{~h} /$ day or not) to obtain stable estimates, as the sample size in each country was small. In order to assess between-country heterogeneity in the association between SB and fast food or carbonated soft drink consumption, we calculated the Higgins's $I^{2}$ which represents the degree of heterogeneity that is not explained by sampling error with a value of $<40 \%$ often considered as negligible and $40-60 \%$ as moderate heterogeneity [19]. A pooled estimate was obtained by combining the estimates for each country into a random effect meta-analysis (overall and by country-income level).

All regression analyses were adjusted for age, sex, food insecurity (proxy of socioeconomic status), and physical activity with the exception of the sex-wise analysis which was not adjusted for sex. The analysis using the overall and sex-wise samples additionally adjusted for country as fixed effects by including dummy variables for each country in the model [28]. All variables were included in the regression analysis as categorical variables with the exception of age (continuous variable). Under 2.3\% of the data were missing for the variables included in the study. Complete case analysis was done. Sampling weights and the clustered sampling design of the surveys were taken into account to obtain nationally representative estimates. In this study, we did not use multilevel models as such analyses can produce biased estimates when used with complex study designs [33]. Results 
Table 1 Survey characteristics and prevalence of fast food consumption, carbonated soft drink consumption, and sedentary behavior

\begin{tabular}{|c|c|c|c|c|c|c|c|}
\hline Country income level & Country & Year & Response rate (\%) & $\mathrm{N}^{\mathrm{a}}$ & $\begin{array}{l}\text { Fast food } \\
\text { consumption }(\%)^{b}\end{array}$ & $\begin{array}{l}\text { Soft drink } \\
\text { consumption (\%) }\end{array}$ & $\begin{array}{l}\text { Sedentary } \\
\text { behavior (\%) }\end{array}$ \\
\hline \multirow[t]{6}{*}{ Low } & Afghanistan & 2014 & 79 & 1493 & 63.3 & 41.1 & 23.3 \\
\hline & Benin & 2009 & 90 & 1170 & 51.8 & 32.1 & 18.4 \\
\hline & Cambodia & 2013 & 85 & 1812 & 25.5 & 45.5 & 10.2 \\
\hline & Mozambique & 2015 & 80 & 668 & 65.5 & 59.8 & 41.0 \\
\hline & Tanzania & 2014 & 87 & 2615 & 35.6 & 47.6 & 20.1 \\
\hline & Total & & & 14,786 & 48.3 & 47.8 & 21.2 \\
\hline \multirow[t]{27}{*}{ Lower middle } & Bangladesh & 2014 & 91 & 2753 & 53.3 & 47.8 & 14.9 \\
\hline & Belize & 2011 & 88 & 1600 & 66.2 & 63.9 & 36.3 \\
\hline & Bolivia & 2012 & 88 & 2804 & 56.9 & 63.1 & 24.3 \\
\hline & East Timor & 2015 & 79 & 1631 & 67.0 & 43.9 & 15.6 \\
\hline & Egypt & 2011 & 85 & 2364 & 49.3 & 54.8 & 27.5 \\
\hline & El Salvador & 2013 & 88 & 1615 & 57.4 & 65.9 & 35.2 \\
\hline & Ghana & 2012 & 82 & 1110 & 69.9 & 55.2 & 18.4 \\
\hline & Guatemala & 2015 & 82 & 3611 & 56.8 & 60.8 & 22.9 \\
\hline & Guyana & 2010 & 76 & 1973 & 56.0 & 70.8 & 35.7 \\
\hline & Honduras & 2012 & 79 & 1486 & 48.0 & 73.6 & 30.3 \\
\hline & Indonesia & 2015 & 94 & 8806 & 54.7 & 29.2 & 24.5 \\
\hline & Kiribati & 2011 & 85 & 1340 & 43.9 & 22.5 & 14.4 \\
\hline & Laos & 2015 & 70 & 1644 & 44.8 & 58.2 & 19.2 \\
\hline & Maldives & 2009 & 80 & 1981 & 34.9 & 32.8 & 42.4 \\
\hline & Mauritania & 2010 & 70 & 1285 & 63.2 & 52.2 & 38.9 \\
\hline & Mongolia & 2013 & 88 & 3707 & 55.2 & 33.1 & 39.6 \\
\hline & Morocco & 2010 & 92 & 2405 & 44.2 & 46.3 & 25.7 \\
\hline & Pakistan & 2009 & 76 & 4998 & 21.0 & 36.6 & 8.2 \\
\hline & Philippines & 2015 & 79 & 6162 & 51.9 & 37.9 & 30.7 \\
\hline & Samoa & 2011 & 79 & 2200 & 78.9 & 53.9 & 38.1 \\
\hline & Solomon Islands & 2011 & 85 & 925 & 65.9 & 44.8 & 26.4 \\
\hline & Sudan & 2012 & 77 & 1401 & 41.5 & 39.2 & 19.7 \\
\hline & Syria & 2010 & 97 & 2929 & 42.8 & 31.1 & 25.3 \\
\hline & Tonga & 2010 & 80 & 1946 & 70.0 & 57.3 & 29.2 \\
\hline & Vanuatu & 2011 & 72 & 852 & 56.4 & 39.8 & 19.0 \\
\hline & Vietnam & 2013 & 96 & 1743 & 29.7 & 34.6 & 34.9 \\
\hline & Total & & & 86,957 & 48.3 & 40.0 & 24.5 \\
\hline \multirow[t]{10}{*}{ Upper middle } & Algeria & 2011 & 98 & 3484 & 51.9 & 77.7 & 26.8 \\
\hline & Antigua \& Barbuda & 2009 & 67 & 1235 & 56.6 & 58.2 & 54.6 \\
\hline & Argentina & 2012 & 71 & 21,528 & 31.5 & 66.0 & 49.9 \\
\hline & Costa Rica & 2009 & 72 & 2265 & 54.4 & 52.6 & 44.2 \\
\hline & Iraq & 2012 & 88 & 1533 & 55.7 & 53.9 & 25.6 \\
\hline & Lebanon & 2011 & 87 & 1982 & 64.6 & 59.2 & 47.2 \\
\hline & Malaysia & 2012 & 89 & 16,273 & 48.3 & 31.3 & 42.7 \\
\hline & Mauritius & 2011 & 82 & 2074 & 54.2 & 39.5 & 39.2 \\
\hline & Namibia & 2013 & 89 & 1936 & 53.9 & 51.4 & 37.2 \\
\hline & Peru & 2010 & 85 & 2359 & 50.0 & 53.4 & 28.6 \\
\hline
\end{tabular}


Table 1 Survey characteristics and prevalence of fast food consumption, carbonated soft drink consumption, and sedentary behavior (Continued)

\begin{tabular}{|c|c|c|c|c|c|c|c|}
\hline Country income level & Country & Year & Response rate (\%) & $N^{a}$ & $\begin{array}{l}\text { Fast food } \\
\text { consumption }(\%)^{\mathrm{b}}\end{array}$ & $\begin{array}{l}\text { Soft drink } \\
\text { consumption }(\%)^{c}\end{array}$ & $\begin{array}{l}\text { Sedentary } \\
\text { behavior (\%) }\end{array}$ \\
\hline & Suriname & 2009 & 89 & 1046 & 62.4 & 80.5 & 40.3 \\
\hline & Thailand & 2015 & 89 & 4132 & 80.1 & 57.9 & 50.7 \\
\hline & Tuvalu & 2013 & 90 & 679 & 44.5 & 54.0 & 15.2 \\
\hline & Total & & & 84,792 & 56.7 & 56.7 & 39.3 \\
\hline
\end{tabular}

${ }^{\text {a }}$ Restricted to those aged $12-15$ years

${ }^{b}$ Fast food consumption referred to having eaten food from a fast food restaurant at least once in the past 7 days

'Soft drink consumption referred to drinking carbonated soft drinks at least once per day in the past 30 days

${ }^{\mathrm{d}}$ Sedentary behavior referred to $\geq 3 \mathrm{~h}$ of sedentary time per day

from the logistic regression analyses are presented as odds ratios (ORs) with 95\% confidence intervals (CIs). The level of statistical significance was set at $p<0.05$.

\section{Results}

Sample characteristics and prevalence of fast food and carbonated soft drink consumption and leisure-time sedentary behavior

The final sample comprised 133,555 adolescents aged $12-15$ years [mean (SD) age 13.8 (1.0) years; $49.0 \%$ females]. The characteristics of each country or survey are provided in Table 1 . The average response rate across all countries was $83.5 \%$. The overall prevalence of fast food consumption (at least once in previous 7 days) and carbonated soft drink consumption (at least once per day during past 30 days) were 49.3 and 43.8\%, respectively. This prevalence varied widely between countries with the ranges being $21.0 \%$ (Pakistan) to $80.1 \%$ (Thailand) for fast food consumption and 22.5\% (Kiribati) to $80.5 \%$ (Suriname) for carbonated soft drinks (Table 1). Overall, $27.0 \%$ of the adolescents engaged in $\geq 3 \mathrm{~h}$ /day of SB per day [range: $8.2 \%$ (Pakistan) to $54.6 \%$ (Antigua \& Barbuda)]. The overall prevalence of SB were: < $1 \mathrm{~h} /$ day $38.7 \% ; 1-2 \mathrm{~h} /$ day $34.3 \% ; 3-4 \mathrm{~h} /$ day $15.8 \%$; $5-8 \mathrm{~h} /$ day $7.7 \%$; and $>8 \mathrm{~h} /$ day $3.6 \%$.

\section{The association of fast food and carbonated soft drink consumption with leisure-time sedentary behavior}

The prevalence of fast food consumption and carbonated soft drink consumption increased with greater time spent sedentary per day (Fig. 1). This was also shown in the multivariable logistic regression analysis where compared to $<1 \mathrm{~h} /$ day of SB, the ORs (95\% CIs) for fast food consumption and carbonated soft drink consumption were $1.45(1.28-1.63)$ and $1.57(1.37-1.81)$ for $>8 \mathrm{~h} /$ day of $\mathrm{SB}$, respectively (Table 2). The associations were similar among boys and girls although the estimates for $>8 \mathrm{~h} /$ day of SB tended to be higher for girls.

The country-wise associations between $\geq 3 \mathrm{~h} /$ day of SB and fast food consumption based on multivariable logistic regression are shown in Fig. 2 . SB of $\geq 3 \mathrm{~h} /$ day was associated with higher odds for fast food consumption (i.e., OR $>1$ ) in 41 of the 44 included countries with significant associations being observed in 25 countries. Particularly strong associations were observed in countries such as Tuvalu $(\mathrm{OR}=2.18 ; 95 \% \mathrm{CI}=1.37-3.47)$, Solomon Islands $(\mathrm{OR}=2.01 ; 95 \% \mathrm{CI}=1.18-3.42)$, and Mongolia $(\mathrm{OR}=1.97 ; 95 \% \mathrm{CI}=1.62-2.39)$. The overall estimate based on a meta-analysis was OR $=1.35(95 \%$ $\mathrm{CI}=1.27-1.43)$ with a moderate level of heterogeneity being observed $\left(I^{2}=62.1 \%\right)$. The corresponding estimates for carbonated soft drink consumption are shown in Fig. 3. SB was associated with carbonated soft drink consumption in 38 countries with significant associations being observed in 22 countries. The strongest associations were observed in Honduras $(\mathrm{OR}=2.17$; $95 \%$ $\mathrm{CI}=1.50-3.15)$, Benin $(\mathrm{OR}=1.41 ; 95 \% \mathrm{CI}=1.19-1.68)$, and Suriname $(\mathrm{OR}=1.74 ; \mathrm{OR}=1.05-2.89)$. The pooled estimate was $\mathrm{OR}=1.26\left(95 \% \mathrm{CI}=1.19-1.34 ; I^{2}=54.3 \%\right)$.

\section{Discussion}

\section{Main findings}

To the best of our knowledge, this is the first multinational LMIC study to investigate the relationship between SB, fast food consumption and soft drink consumption in adolescents. We found that overall, $27 \%$ of adolescents spend $\geq 3 \mathrm{~h} /$ day of their leisure time being sedentary, $49 \%$ of adolescents had consumed fast food at least once within the past week, while $44 \%$ of adolescents had consumed a carbonated soft drink at least once per day in the past month. We also found that SB of $\geq 3 \mathrm{~h} /$ day was associated with higher odds for both fast food consumption and soft drink consumption in the majority of the 44 LMICs. Overall, a moderate level of between-country heterogeneity was observed but there were no major differences in the magnitude of the association by country income levels. Furthermore, consumption of fast foods and soft drinks appeared to increase with an increased time spent being sedentary. 


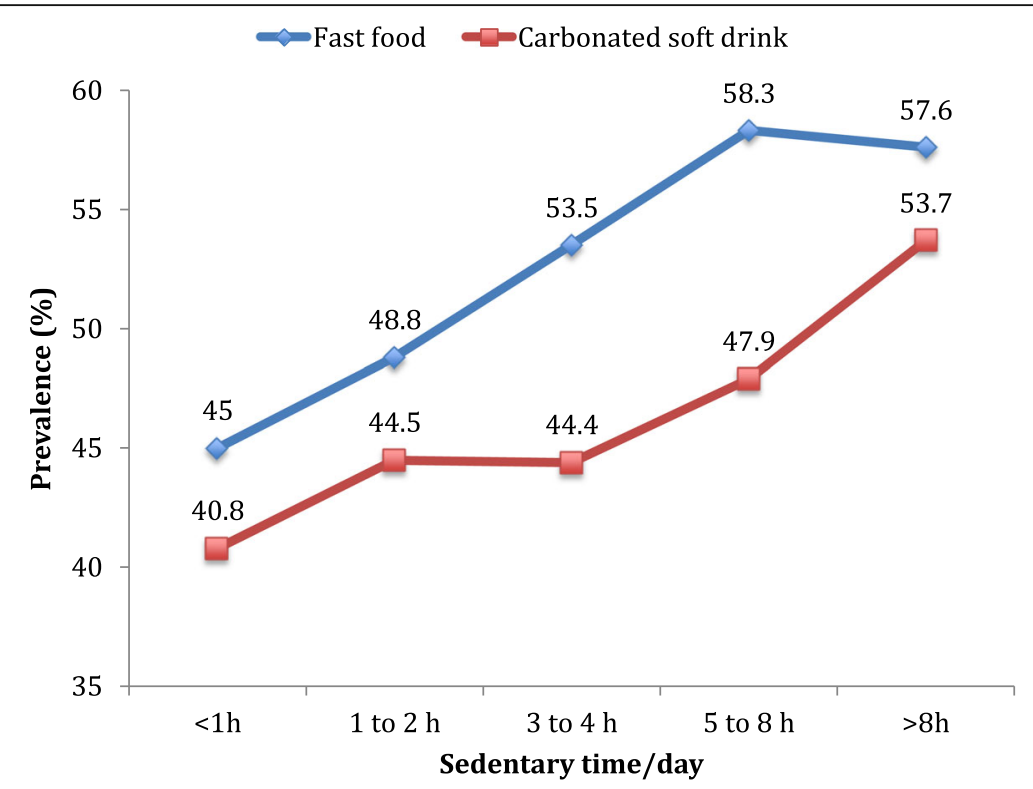

Fig. 1 Prevalence of fast food and carbonated soft drink consumption by time spent sedentary per day. Fast food consumption referred to having eaten food from a fast food restaurant at least once in the past 7 days. Carbonated soft drink consumption referred to drinking carbonated soft drinks at least once per day in the past 30 days

\section{Interpretation}

In general, the prevalence of fast food and soft drink consumption were comparable to high-income countries. For example, one multinational study from high-income countries found that frequent consumption of fast food (once or twice a week) among adolescents aged 13-14 years was 39\% [7]. The overall prevalence of soft drink consumption was also similar to those previously reported from high-income countries [14]. This suggests that fast food and carbonated soft drink consumption can no longer be considered a problem of high-income countries alone. In addition, the fact that $27 \%$ of adolescents in our LMIC sample were sedentary for $3 \mathrm{~h}$ a day or more (excluding time spent at school or on homework) also

Table 2 Association of time spent sedentary with fast food and carbonated soft drink consumption (outcomes) estimated by multivariable logistic regression

\begin{tabular}{|c|c|c|c|c|c|c|}
\hline \multicolumn{7}{|l|}{ Fast food consumption ${ }^{a}$} \\
\hline Time spent sedentary & Overall & & Male & & Female & \\
\hline$<1 \mathrm{~h} /$ day & 1.00 & & 1.00 & & 1.00 & \\
\hline 1 to $2 \mathrm{~h} /$ day & $1.16^{* * *}$ & {$[1.08,1.25]$} & $1.14^{*}$ & {$[1.01,1.30]$} & $1.17^{* * *}$ & {$[1.07,1.28]$} \\
\hline 3 to 4 h/day & $1.36^{* * *}$ & {$[1.26,1.48]$} & $1.34^{* * *}$ & {$[1.19,1.51]$} & $1.36^{* * *}$ & {$[1.23,1.49]$} \\
\hline 5 to 8 h/day & $1.54^{* * *}$ & {$[1.36,1.75]$} & $1.52^{* * *}$ & {$[1.25,1.84]$} & $1.51^{* * *}$ & {$[1.31,1.74]$} \\
\hline$>8$ h/day & $1.45^{* * *}$ & {$[1.28,1.63]$} & $1.27^{* *}$ & {$[1.06,1.52]$} & $1.61^{* * *}$ & {$[1.38,1.88]$} \\
\hline \multicolumn{7}{|c|}{ Carbonated soft drink consumption ${ }^{b}$} \\
\hline Time spent sedentary & Overall & & Male & & Female & \\
\hline$<1$ h/day & 1.00 & & 1.00 & & 1.00 & \\
\hline 1 to $2 \mathrm{~h} /$ day & $1.17^{* * *}$ & {$[1.09,1.25]$} & $1.17^{* *}$ & {$[1.05,1.31]$} & $1.15^{* *}$ & {$[1.04,1.26]$} \\
\hline 3 to 4 h/day & $1.14^{* * *}$ & {$[1.06,1.22]$} & $1.15^{*}$ & {$[1.03,1.28]$} & $1.13^{*}$ & {$[1.02,1.25]$} \\
\hline 5 to 8 h/day & $1.24^{* * *}$ & {$[1.10,1.40]$} & $1.24^{*}$ & {$[1.04,1.47]$} & $1.21^{*}$ & {$[1.05,1.39]$} \\
\hline$>8$ h/day & $1.57^{* * *}$ & {$[1.37,1.81]$} & $1.29^{*}$ & {$[1.05,1.60]$} & $1.91^{* * *}$ & {$[1.60,2.28]$} \\
\hline
\end{tabular}

Data are odds ratio [95\% confidence interval]

Models are adjusted for age, socioeconomic status (food insecurity), physical activity, and country. Overall estimate is additionally adjusted for sex

${ }^{\text {a }}$ Fast food consumption referred to having eaten food from a fast food restaurant at least once in the past 7 days

${ }^{\mathrm{b}}$ Carbonated soft drink consumption referred to drinking carbonated soft drinks at least once per day in the past 30 days

${ }^{*} p<0.05,{ }^{* *} p<0.01,{ }^{* * *} p<0.001$ 


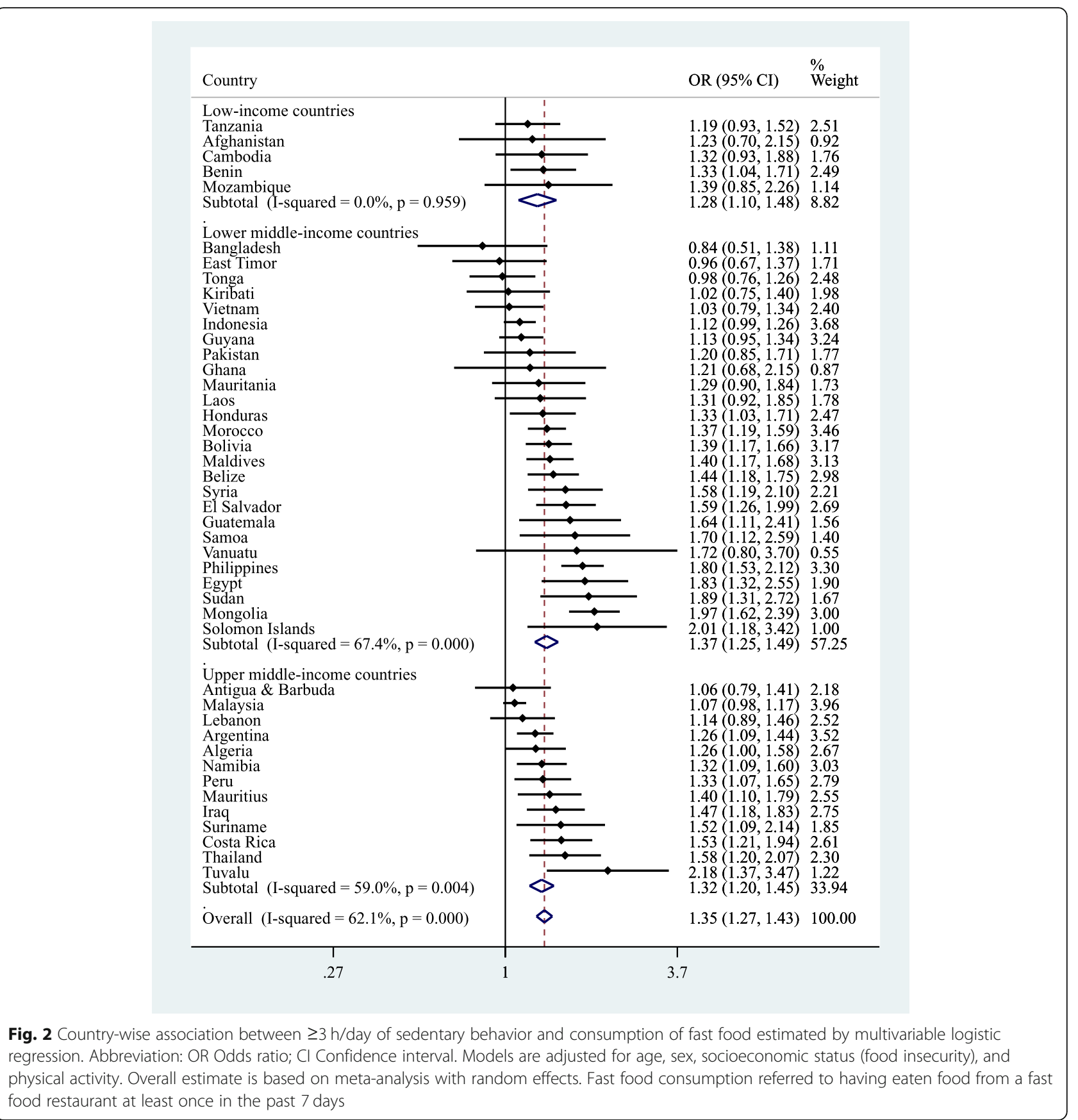

highlight the importance of addressing health risk factors among adolescence in this context.

In our study, greater leisure-time SB was associated with greater fast food and carbonated soft drink consumption. This is in line with studies conducted in high-income countries. For example, among Australian adolescents, total screen time (i.e. not only television viewing) $(\mathrm{OR}=1.80 ; 95 \% \mathrm{CI} 1.33,2.44, p<.05)$ and recreational computer use $(\mathrm{OR}=1.50 ; 95 \% \mathrm{CI} 1.13,2.00$, $p<.05)$ were positively associated with weekly consumption of fast foods, while total screen time was also associated with greater consumption of sugar-sweetened beverages $(\mathrm{OR}=1.11 ; \mathrm{CI} 1.11-1.98, p<.05)$, as were television time and e-game time [14]. In a European sample (Greece, Norway, Hungary, Belgium, Spain, Switzerland), there was a positive association between mins/day of television viewing and $\mathrm{mL} /$ day of soft drink consumption. Interestingly, these results were found to be independent of individual and home environmental correlates of soft drink consumption, such as attitude towards soft drink consumption and parental modeling, respectively [16]. 


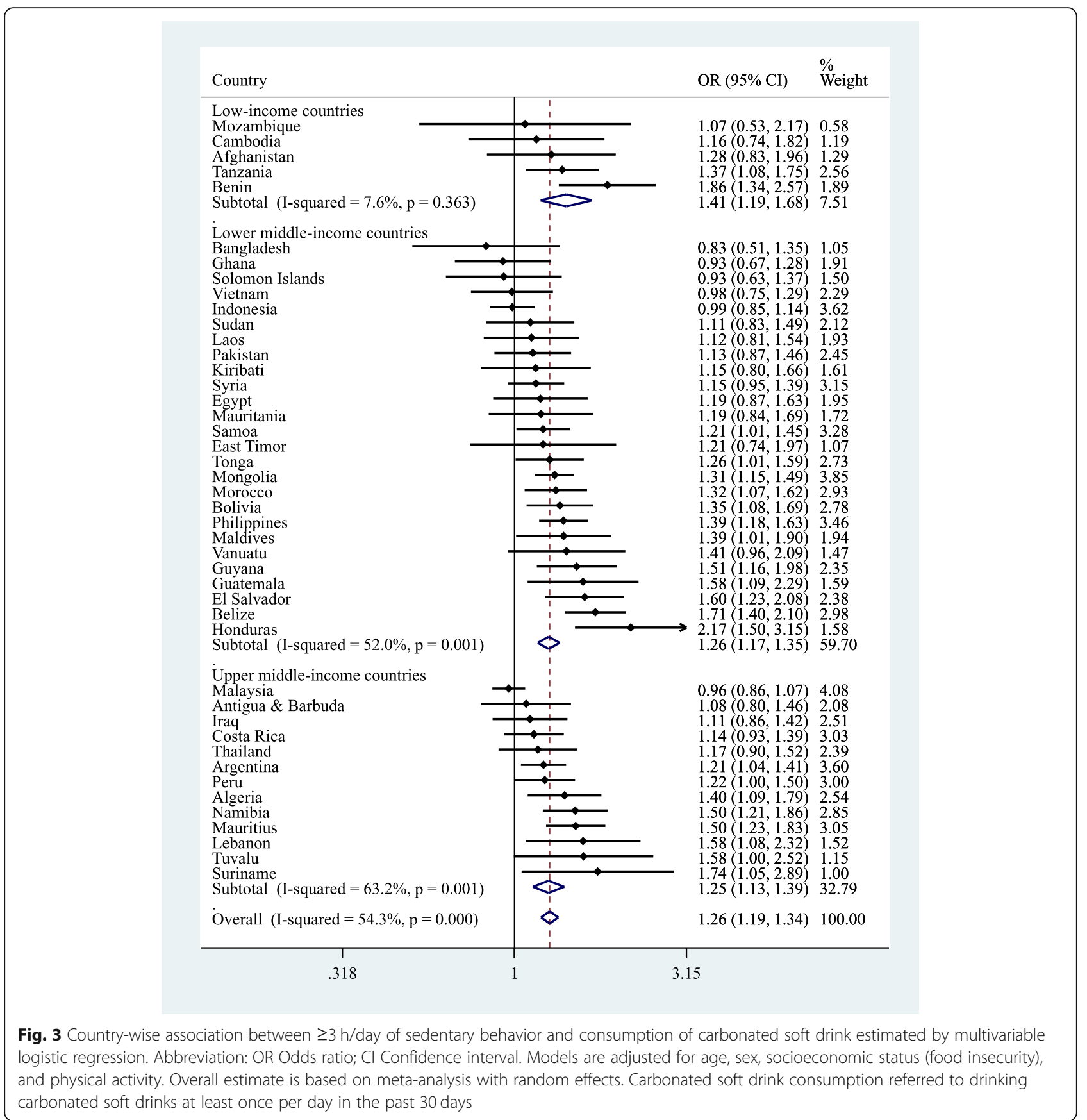

Fast food and carbonated soft drink consumption were both associated with time spent sedentary in the majority of the countries studied although a moderate level of between-country heterogeneity was observed. The reason for the moderate level of between-country heterogeneity is unknown but may be associated with factors such as difference in the content/context of SB or availability of fast food/carbonated soft drinks, or culture. For example, it has been established that youth from India, but also Lebanon are first exposed to fast foods through television commercials, and as such, differences in household ownership of televisions may play a role in this relationship [11, 23]. It has also been found in a European study that youth from lower-SES families are more likely to consume unhealthy drinks during television viewing [34]. Furthermore, it may be that changes in weather, temperature, access to poor foods and technological transitions might also be important factors [25].

The relationship between SB and soft drink or fast food consumption could be explained by factors such as mindless eating, advertising of fast foods and soft drinks 
during viewing times that are common for adolescents, or the use of popular youth programs as sponsors for fast foods and soft drinks [14]. Indeed, it may also be that computers and televisions act as a distractor, and that SB is accompanied by a cluster of other unhealthy behaviors such as the consumption of unhealthy food and drinks, and excessive SB may result in the creation of automatic cues for such dietary habits $[6,12]$. It has been found that among adolescents, soft drink consumption and SB cluster together, and are related to each other in a habitual way, such that those who have a stronger habit of television viewing also have a stronger habit of soft drink consumption [12]. As such, the deleterious associations between SB and adverse physical health outcomes such as obesity may be at least partially accounted for by the co-occurrence with other unhealthy lifestyle behaviors such as fast food consumption [5]. Thus, also in LMICs, interventions may need to focus on addressing the habitual component of co-occurring carbonated soft drink/fast food consumption and SB.

\section{Policy implications and areas for future research}

Taken together, our findings can be used to inform interventions targeted at decreasing $\mathrm{SB}$, fast food and soft drink consumption among adolescents in LMICs. Importantly, although the associations between the three health behaviors were similar between sexes, the estimates for fast food and soft drink consumption with $>8 \mathrm{~h} /$ day of SB tended to be higher for girls. This suggests that girls may be in greater need than boys of intervention. Furthermore, these relationships appear to cluster together, so it may be that targeting one aspect, such as SB, will have positive outcomes in turn on fast food and soda drink consumption [13]. Future research and interventions should take into account the clustered nature of the relationship between SB, fast food consumption and soft drink consumption. Interventions using text messages as prompts to change health behaviors have been successful in the past (e.g. Cole-Lewis \& Kershaw [10]). Evidence is emerging that also in LMICs mobile phones are an effective way to reach young people and to achieve knowledge and behavior change [21].

Given that the findings of the current study are similar to findings in high-income countries, many of which have guidelines or recommendations on limiting SB among adolescents (i.e., [1]), the creation of similar recommendations in LMICs may be warranted. Finally, as previous research has found that the majority of screen time occurs in the home and that most of the food adolescents consume is provided by their families, interventions are needed to encourage healthier eating habits while simultaneously discouraging sitting and television viewing, in the home context [14].

\section{Limitations}

While this study provides novel findings especially in the LMIC context, it does have some limitations. First, although the overall response rate was high, there was some variation between countries with the response rates ranging from 67\% (Antigua \& Barbuda) to 98\% (Algeria). Thus, it is possible that some level of bias was introduced in countries with low response rates. However, the use of sampling weights in the analysis is likely to have mitigated this potential bias. Second, the self-reported nature of the study may have resulted in adolescents inaccurately reporting their health behaviors, which may have biased the associations we found, and as such these findings must be taken in light of this. Third, the type and nature of SB were not measured. Past research has found that different types of SB may differentially affect food behaviors $[14,20]$. For example, our study was on leisure-time SB and did not include SB during school time or while completing homework but it has been found that SB during homework completion has actually been linked to positive dietary behaviors such as increased fruit and vegetable consumption [20]. Relatedly, because students were instructed to exclude time spent at school or when doing homework when answering the question on time spent sedentary per day, this may have been difficult to calculate for some students. Furthermore, there may not have been many students who can spend $>8 \mathrm{~h} /$ day of SB out of school or when not doing homework and these students may have been a group with particular characteristics such as those attending schools with short schooling hours. In addition, only adolescents attending school were included in this study. Thus, our study results may not be generalizable to those who do not attend school. Finally, the cross-sectional nature of this study means that causation and directionality cannot be inferred.

\section{Conclusion}

In conclusion, this is the first multinational LMIC study to investigate the relationship between SB, fast food consumption and soft drink consumption in adolescents. The results demonstrate that among adolescents in LMICs, rates of fast-food consumption and soft drink consumption increased with increasing time spent sedentary. There were some differences in the findings between countries and sexes, suggesting that context- or sex-specific strategies may be necessary. Future research is needed to confirm the causal aspects of this relationship and to specifically examine the exact context of SB and how this relates to unhealthy dietary habits among adolescents in LMICs for the establishment of effective strategies to reduce SB and poor dietary habits. 


\section{Acknowledgements}

Not applicable.

\section{Funding}

Ai Koyanagi's work is supported by the Miguel Servet contract financed by the CP13/00150 and PI15/00862 projects, integrated into the National R+D + I and funded by the ISCIII - General Branch Evaluation and Promotion of Health Research - and the European Regional Development Fund (ERDFFEDER). Brendon Stubbs is in part supported by the National Institute for Health Research (NIHR) Collaboration for Leadership in Applied Health Research \& Care Funding scheme, by the Maudsley Charity and by the NIHR Maudsley Biomedical Research Centre at South London and Maudsley NHS Foundation Trust and King's College London. Brendon Stubbs is also supported by Health Education England and the National Institute for Health Research HEE/NIHR ICA Programme Clinical Lectureship (ICA-CL-2017-03001). Catherine M. Sabiston is supported by a Canada Research Chairs award. Garcia Ashdown-Franks receives funding from Mitacs Globalink. These funders had no role in: design and conduct of the study; collection, management, analysis, and interpretation of the data; and preparation, review, or approval of the manuscript.

\section{Availability of data and materials}

The datasets generated and/or analysed during the current study are available in the World Health Organization repository, https://www.who.int/ ncds/surveillance/gshs/en/.

\section{Authors' contributions}

Conceived study idea, BS, DV, AK, GAF. Analysis and interpretation of data BS, DV, AK, GAF. Wrote first draft of manuscript BS, DV, AK, GAF. Provided critical comments and approved the manuscript - all authors. Approved final version - all authors.

\section{Ethics approval and consent to participate}

All GSHS surveys were approved, in each country, by both a national government administration (most often the Ministry of Health or Education) and an institutional review board or ethics committee. Student privacy was protected through anonymous and voluntary participation, and written informed consent was obtained as appropriate from the students, parents and/or school officials.

\section{Consent for publication}

Not applicable.

\section{Competing interests}

The authors declare that they have no competing interests.

\section{Publisher's Note}

Springer Nature remains neutral with regard to jurisdictional claims in published maps and institutional affiliations.

\section{Author details}

'Department of Psychological Medicine, Institute of Psychiatry, Psychology and Neuroscience, King's College London, De Crespigny Park, Box, London SE5 8AF, UK. ${ }^{2}$ Department of Exercise Sciences, University of Toronto, 55 Harbord Street, Toronto, Ontario M5S 2W6, Canada. ${ }^{3}$ Department of Rehabilitation Sciences, KU Leuven, Leuven, Belgium. ${ }^{4} \mathrm{KU}$ Leuven, University Psychiatric Center KU Leuven, Kortenberg, Belgium. ${ }^{5} \mathrm{NICM}$ Health Research Institute, Western Sydney University, Sydney, Australia. ${ }^{6}$ Division of Psychology and Mental Health, Faculty of Biology, Medicine and Health, University of Manchester, Manchester, UK. ${ }^{7}$ The Cambridge Centre for Sport and Exercise Sciences, Anglia Ruskin University, Cambridge, UK. ${ }^{8}$ Physiotherapy Department, South London and Maudsley National Health Services Foundation Trust, London, UK. ${ }^{9}$ Research and Development Unit, Parc Sanitari Sant Joan de Déu, CIBERSAM, Dr. Antoni Pujadas, Barcelona, Spain. ${ }^{10}$ ICREA, Pg. Lluis Companys, 23 Barcelona, Spain.
Received: 14 January 2019 Accepted: 4 April 2019

Published online: 23 April 2019

\section{References}

1. Australian Government, Department of Health. Make Your Move - Sit Less, Be Active for Life! Australia's Physical Activity and Sedentary Behaviour Guidelines for Young People (13-17 years). Canberra: Commonwealth of Australia; 2014.

2. Balogun O, Koyanagi A, Stickley A, Gilmour S, Shibuya K. Alcohol consumption and psychological distress in adolescents: a multi-country study. Journal of adolescent health. 2014;54(2):228-34.

3. Basu S, McKee M, Galea G, Stuckler D. Relationship of soft drink consumption to global overweight, obesity, and diabetes: a cross-national analysis of 75 countries. Am J Public Health. 2013;103(11):2071-7.

4. Biswas A, Oh PI, Faulkner GE, Bajaj RR, Silver MA, Mitchell MS, Alter DA. Sedentary time and its association with risk for disease incidence, mortality, and hospitalization in adults: a systematic review and meta-analysis. Ann Intern Med. 2015;162(2):123-32.

5. Borghese MM, Tremblay MS, Leduc G, Boyer C, Bélanger P, LeBlanc AG, Francis C, Chaput JP. Television viewing and food intake during television viewing in normal-weight, overweight and obese 9-to 11-year-old Canadian children: a cross-sectional analysis. J Nutri Sc. 2015;4:e8.

6. Boulos R, Vikre EK, Oppenheimer S, Chang H, Kanarek RB. ObesiTV: how television is influencing the obesity epidemic. Physiol Behav. 2012;107(1):146-53.

7. Braithwaite I, Stewart AW, Hancox RJ, Beasley R, Murphy R, Mitchell EA. ISAAC phase three study group. Fast-food consumption and body mass index in children and adolescents: an international cross-sectional study. BMJ Open. 2014;4(12):e005813.

8. Bremer AA, Lustig RH. Effects of sugar-sweetened beverages on children. Pediatr Ann. 2012;41(1):26-30.

9. Brener ND, Collins JL, Kann L, Warren CW, Williams BI. Reliability of the youth risk behavior survey questionnaire. Am J Epidemiol. 1995;141(6):575-80.

10. Cole-Lewis $H$, Kershaw T. Text messaging as a tool for behavior change in disease prevention and management. Epidemiol Rev. 2010;32(1):56-69.

11. Dalton MA, Longacre MR, Drake KM, Cleveland LP, Harris JL, Hendricks K, Titus $\sqcup$. Child-targeted fast-food television advertising exposure is linked with fast-food intake among pre-school children. Public Health Nutr. 2017;20(9):1548-56.

12. de Bruijn GJ, van den Putte B. Adolescent soft drink consumption, television viewing and habit strength. Investigating clustering effects in the theory of planned behaviour. Appetite. 2009;53(1):66-75.

13. Dumuid D, Olds T, Lewis LK, Martin-Fernández JA, Katzmarzyk PT, Barreira T, Broyles ST, Chaput JP, Fogelholm M, Hu G, Kuriyan R. Health-related quality of life and lifestyle behavior clusters in school-aged children from 12 countries. J Pediatr. 2017;183:178-83.

14. Fletcher EA, McNaughton SA, Crawford D, Cleland V, Della Gatta J, Hatt J, Dollman J, Timperio A. Associations between sedentary behaviours and dietary intakes among adolescents. Public Health Nutr. 2018;21(6):1115-22.

15. Ford ND, Patel SA, Narayan KV. Obesity in low-and middle-income countries: burden, drivers, and emerging challenges. Annu Rev Public Health. 2017;38:145-64.

16. Gebremariam MK, Chinapaw MJ, Bringolf-Isler B, Bere E, Kovacs E, Verloigne M, Stok FM, Manios Y, Brug J, Lien N. Screen-based sedentary time: association with soft drink consumption and the moderating effect of parental education in European children: the ENERGY study. PLoS One. 2017;12(2):e0171537.

17. Guthold R, Cowan MJ, Autenrieth CS, Kann L, Riley LM. Physical activity and sedentary behavior among schoolchildren: a 34-country comparison. J Pediatr. 2010;157(1):43-9.

18. Hancox RJ, Milne BJ, Poulton R. Association between child and adolescent television viewing and adult health: a longitudinal birth cohort study. Lancet. 2004;364(9430):257-62.

19. Higgins JP, Thompson SG. Quantifying heterogeneity in a meta-analysis Stat Med. 2002;21(11):1539-58.

20. Hobbs M, Pearson N, Foster PJ, Biddle SJ. Sedentary behaviour and diet across the lifespan: an updated systematic review. Br J Sports Med. 2015;49(18):1179-88.

21. Ippoliti NB, L'Engle K. Meet us on the phone: mobile phone programs for adolescent sexual and reproductive health in low-to-middle income countries. Reprod Health. 2017;14(1):11. 
22. Janssen HG, Davies IG, Richardson LD, Stevenson L. Determinants of takeaway and fast food consumption: a narrative review. Nutr Res Rev. 2018;31(1):16-34.

23. Joseph N, Nelliyanil M, Rai S, YP RB, Kotian SM, Ghosh T, Singh M. Fast food consumption pattern and its association with overweight among high school boys in Mangalore city of southern India. J Clin Diagn Res: JCDR. 2015;9(5):LC13.

24. LeBlanc AG, Katzmarzyk PT, Barreira TV, Broyles ST, Chaput JP, Church TS, Fogelholm M, Harrington DM, Hu G, Kuriyan R, Kurpad A. Correlates of total sedentary time and screen time in 9-11 year-old children around the world: the international study of childhood obesity, lifestyle and the environment. PLoS One. 2015;10(6):e0129622.

25. Lewis LK, Maher C, Belanger K, Tremblay M, Chaput JP, Olds T. At the mercy of the gods: associations between weather, physical activity, and sedentary time in children. Pediatr Exerc Sci. 2016;28(1):152-63.

26. Ludwig DS, Peterson KE, Gortmaker SL. Relation between consumption of sugar-sweetened drinks and childhood obesity: a prospective, observational analysis. Lancet. 2001;357(9255):505-8.

27. Malik VS, Willett WC, Hu FB. Global obesity: trends, risk factors and policy implications. Nat Rev Endocrinol. 2013;9(1):13.

28. McKinnon B, Gariépy G, Sentenac M, Elgar FJ. Adolescent suicidal behaviours in 32 low-and middle-income countries. Bull World Health Organ. 2016;94(5):340.

29. Mitchell JA, Byun W. Sedentary behavior and health outcomes in children and adolescents. Am J Lifestyle Med. 2014;8(3):173-99.

30. New Zealand Beverage Guidance Panel. POLICY BRIEF : Options to Reduce Sugar Sweetened Beverage (SSB) Consumption in New Zealand; 2014. doi: https://doi.org/10.1177/0022146514533086.

31. Poskitt EM. Childhood obesity in low-and middle-income countries. Paediatr Int Child Health. 2014;34(4):239-49.

32. Prochaska JJ, Sallis JF, Long B. A physical activity screening measure for use with adolescents in primary care. Archives Pediatr Adolesc Med. 2001;155(5):554-9.

33. Rabe-Hesketh S, Skrondal A. Multilevel modelling of complex survey data. J Royal Stat Soc: Series A (Statistics in Society). 2006;169(4):805-27.

34. Rey-López JP, Vicente-Rodríguez G, Répasy J, Mesana MI, Ruiz JR, Ortega FB, Kafatos A, Huybrechts I, Cuenca-Garcia M, León JF, Gonzalez-Gross M. Food and drink intake during television viewing in adolescents: the healthy lifestyle in Europe by nutrition in adolescence (HELENA) study. Public Health Nutr. 2011;14(9):1563-9.

35. Stuckler D, Nestle M. Big food, food systems, and global health. PLoS medicine. 2012;9(6):e1001242.

36. The World Bank Group. How does the World Bank classify countries? 2018. https://datahelpdesk.worldbank.org/knowledgebase/articles/378834-howdoes-the-world-bankclassify-countries.

37. World Health Organization. Global status report on noncommunicable diseases 2010. Geneva: World Health Organization; 2011.

Ready to submit your research? Choose BMC and benefit from:

- fast, convenient online submission

- thorough peer review by experienced researchers in your field

- rapid publication on acceptance

- support for research data, including large and complex data types

- gold Open Access which fosters wider collaboration and increased citations

- maximum visibility for your research: over $100 \mathrm{M}$ website views per year

At BMC, research is always in progress.

Learn more biomedcentral.com/submissions 